\title{
Evaluation of Radiopacity, pH, Release of Calcium lons, and Flow of a Bioceramic Root Canal Sealer
}

\author{
George Táccio de Miranda Candeiro, DDS, MSc, * Fabrícia Campelo Correia, DDS, ${ }^{\star}$ \\ Marco Antônio Húngaro Duarte, DDS, MSc, PbD, ${ }^{\neq}$ \\ Danieli Colaço Ribeiro-Siqueira, DDS, MSc, PbD, * and Giulio Gavini, DDS, MSc, PhD ${ }^{*}$
}

\section{Ahstract}

Introduction: The aim of the present study was to evaluate the physicochemical properties of a bioceramic root canal sealer, Endosequence BC Sealer. Radiopacity, pH, release of calcium ions $\left(\mathrm{Ca}^{2+}\right)$, and flow were analyzed, and the results were compared with $\mathrm{AH}$ Plus cement. Methods: Radiopacity and flow were evaluated according to ISO 6876/2001 standards. For the radiopacity analysis, metallic rings with $10-\mathrm{mm}$ diameter and 1-mm thickness were filled with cements. The radiopacity value was determined according to radiographic density ( $\mathrm{mm} \mathrm{Al}$ ). The flow test was performed with $0.05 \mathrm{~mL}$ of cement placed on a glass plate. A 120-g weight was carefully placed over the cement. The largest and smallest diameters of the disks formed were measured by using a digital caliper. The release of $\mathrm{Ca}^{2+}$ and $\mathrm{pH}$ were measured at periods of 3, 24, 72,168 , and 240 hours with spectrophotometer and $\mathrm{pH}$ meter, respectively. Data were analyzed by analysis of variance and Tukey test $(P<.05)$. Results: The bioceramic endodontic cement showed radiopacity (3.84 $\mathrm{mm} \mathrm{Al)} \mathrm{significantly} \mathrm{lower} \mathrm{than} \mathrm{that} \mathrm{of} \mathrm{AH} \mathrm{Plus} \mathrm{(6.90}$ $\mathrm{mm} \mathrm{Al}$ ). The $\mathrm{pH}$ analysis showed that Endosequence $\mathrm{BC}$ Sealer showed $\mathrm{pH}$ and release of $\mathrm{Ca}^{2+}$ greater than those of $\mathrm{AH}$ Plus $(P<.05)$ during the experimental periods. The flow test revealed that $B C$ Sealer and $A H$ Plus presented flow of $26.96 \mathrm{~mm}$ and $21.17 \mathrm{~mm}$, respectively $(P<.05)$. Conclusions: Endosequence BC Sealer showed radiopacity and flow according to ISO 6876/ 2001 recommendations. The other physicochemical properties analyzed demonstrated favorable values for a root canal sealer. (J Endod 2012;38:842-845)

\section{Key Words}

Bioceramic material, calcium ions release, flow, $\mathrm{pH}$, radiopacity, root canal cements
Dioceramic-based materials have been recently introduced in endodontics, mainly as repair cement $(1,2)$ and as root canal sealer $(3-5)$. Bioceramics are the result of the combination between calcium silicate and calcium phosphate that are applicable for biomedical and dental use (3). According to manufacturers, bioceramic materials show alkaline $\mathrm{pH}$, antibacterial activity, radiopacity, and biocompatibility. Thus, the main advantages of bioceramic materials in dental application are related with their physical and biological properties. Bioceramics are biocompatible, nontoxic, nonshrinking, and chemically stable within the biological environment. Another advantage of the material is its ability during the setting process to form hydroxyapatite and ultimately a bond between dentin and filling material $(5,6)$.

Endosequence BC Sealer (Brasseler USA, Savannah, GA) is a premixed bioceramic endodontic sealer that presents in its composition zirconium oxide, calcium silicates, calcium phosphate monobasic, calcium hydroxide, filler, and thickening agents (4). Therefore, Endosequence BC Sealer has been designed to harden only when exposed to an environment such as dentinal tubules (6). Dentin is composed of approximately $20 \%$ (by volume) of water $(7)$, and this water causes the material setting $(5,8)$. However, up to now, there are limited independent publications about the physicochemical and biological properties of bioceramic endodontic sealer and its possible use in clinical practice.

Thus the aim of the present study was to analyze radiopacity, $\mathrm{pH}$, release of calcium ions $\left(\mathrm{Ca}^{2+}\right)$, and flow of Endosequence $\mathrm{BC}$ Sealer and to compare it with AH Plus (Dentsply De Trey Gmbh, Konstanz, Germany).

\section{Materials and Methods}

Radiopacity and flow evaluations were performed according to ISO 6876/2001 specifications (9). Release of calcium ions $\left(\mathrm{Ca}^{2+}\right)$ and $\mathrm{pH}$ were measured at different periods. AH Plus cement was mixed according to recommendations from the manufacturer. Endosequence BC is premixed, so further manipulations were unnecessary. Table 1 demonstrates the constitution of cements.

\section{Radiopacity Test}

Cylindrical samples from each material were manufactured by pouring the manipulated cements into metallic rings measuring $10 \mathrm{~mm}$ in diameter and $1 \mathrm{~mm}$ in thickness. Five samples of each material were manufactured. The filled rings were kept at $37^{\circ} \mathrm{C}$ until cements were completely set. The specimens were then removed, and the thickness was checked with a digital caliper (Mitutoyo Corp, Tokyo, Japan). The dentin cylinders were obtained by cutting noncarious roots freshly extracted from human teeth in 1-mm-

From the *Discipline of Endodontics, Department of Dentistry, Faculty of Dentistry, University of São Paulo, São Paulo, São Paulo; ${ }^{\dagger}$ Faculty of Pharmacy, Dentistry and Nursing, Federal University of Ceará, Fortaleza, Ceará; and ${ }^{\ddagger}$ Discipline of Endodontics, Department of Restorative Dentistry, Endodontics and Dental Materials, Dental School of Bauru, University of São Paulo, Bauru, São Paulo, Brazil.

Address requests for reprints to Prof Dr Giulio Gavini, School of Dentistry, University of Sao Paulo, Department of Restorative Dentistry, Endodontics Division, Av. Prof. Lineu Prestes, 2227, CEP 05508-000, São Paulo, SP, Brazil. E-mail address: ggavini@usp.br

$0099-2399 / \$$ - see front matter

Copyright () 2012 American Association of Endodontists.

doi:10.1016/j.joen.2012.02.029 
Basic Research-Technology

TABLE 1. Materials Tested and Their Composition

\begin{tabular}{llc}
\hline \multicolumn{1}{c}{ Material } & \multicolumn{1}{c}{ Composition } & Manufacturer \\
\hline Endosequence BC Sealer & $\begin{array}{l}\text { Zirconium oxide, calcium silicates, calcium } \\
\text { phosphate monobasic, calcium hydroxide, filler } \\
\text { and thickening agents. } \\
\text { Epoxy paste: diepoxy, calcium tungstate, zirconium } \\
\text { oxide, aerosol, and dye. } \\
\text { Amine paste: 1-adamantane amine, N.N'dibenzyl-5 } \\
\text { oxanonandiamine-1,9, TCD-diamine, calcium } \\
\text { tungstate, zirconium oxide, aerosol, and silicon oil. }\end{array}$ & Dentsply De Trey Gmbh (Konstanz, Germany) \\
\hline
\end{tabular}

thick sections with a water-cooled silicon carbide disk. The dentin disks were for the purpose of radiographic comparison with the sealers tested and the aluminum wedge. The disk thickness was checked with a digital caliper. All cement and dentin specimens were placed on 5 occlusal films (Insight; Kodak Company, Rochester, NY) along with an aluminum step-wedge graduated from 1-10 $\mathrm{mm} \mathrm{Al}$ (in 1-mm increments). Radiographs were taken by using a radiographic unit (Gnatus XR 6010, Ribeirão Preto, SP, Brazil) operating at $60 \mathrm{kV}, 10 \mathrm{~mA}$, with exposure set at 0.3 seconds and a focus-film distance of $30 \mathrm{~cm}$. After processing, the radiographs were digitized by using Nikon D40 with Nikon 50-mm macro lens (Nikon D40, Tokyo, Japan) and imported into Digora 1.51 for Windows software (Orion Corporation Soredex, Helsinki, Finland). The radiopacity value was determined according to the radiographic density, which was also converted into millimeters of aluminum. Conversion was performed as described by Duarte et al (10).

\section{ph Analysis}

Shortly after manipulation, the cements were carefully placed in plastic tubes (polyethylene) measuring $1.0 \mathrm{~mm}$ in internal diameter and $10.0 \mathrm{~mm}$ in length with only one open end, with the aid of a lentulo spiral. Periapical radiographs were taken to confirm the complete filling of tubes and the absence of bubbles. Eight samples were used for each material. After being filled and weighed, each specimen was immediately immersed in test glass tubes containing $10 \mathrm{~mL}$ of deionized water (Permution, Curitiba, PR, Brazil), which were then sealed with Parafilm (American National Can, Menasha, WI) and placed in oven at $37^{\circ} \mathrm{C}$ (Farmen, São Paulo, SP, Brazil), being kept throughout the study period. The $\mathrm{pH}$ was measured with $\mathrm{pH}$ meter (QM-400; Quimis, São Paulo, SP, Brazil) previously calibrated with solutions of known $\mathrm{pH}$ $(4,7,10)$. Previous to the immersion of specimens, the $\mathrm{pH}$ of the deionized water was verified, showing $\mathrm{pH}$ 6.9. After removal of the specimens, the test tubes were shaken for 5 seconds before $\mathrm{pH}$ measurement. Evaluations were performed at periods of 3, 24, 72, 168 , and 240 hours. Fresh tubes containing deionized water were used for each evaluation period.

\section{Calcium Ion Release}

The release of calcium ions $\left(\mathrm{Ca}^{2+}\right)$ was measured by using an atomic absorption spectrophotometer (AA6800; Shimadzu, Tokyo, Japan). The conditions for use of the appliance were determined following the manufacturer's instructions by using a wavelength of
$422.70 \mathrm{~nm}$, gap of $0.2 \mathrm{~nm}$, current of $10 \mathrm{~mA}$ in the lamp, and slightly reducing stoichiometry, kept by an acetylene flow of $2.0 \mathrm{~L}$ per minute, supported by the air. A lanthanum chloride solution at concentration of $10 \mathrm{~g} / \mathrm{L}$ was used to eliminate the interference of phosphates and sulfates and the possibility of formation of refractory oxides. A standard stock solution of $10 \mathrm{mg} / \mathrm{dL}$ was diluted in water to achieve the following concentrations: $0.025,0.05,0.1,0.25,0.5$, and $1.0 \mathrm{mg} / \mathrm{dL}$. The results were calculated according to a standard curve established on the basis of solutions with predefined calcium concentrations.

\section{Flow Analysis}

Final volume of $0.05 \mathrm{~mL}$ of cement was prepared and put on glass plate by using a tuberculin syringe of $1.0 \mathrm{~mL}$. At $180 \pm 5$ seconds after the onset of the mixing, the second glass plate $(50 \times 50 \times 3.2 \mathrm{~mm}$ and $20 \mathrm{~g}$ of weight) was carefully and centrally placed on top of the sealer, followed by weighting of approximately $100 \mathrm{~g}$ to make a total mass on the plate of $120 \mathrm{~g}$. Ten minutes after the onset of the mixing, the weight was removed, and the maximum and minimum diameters of the compressed sealer disks were measured by a digital caliper (Mitutoyo MTI Corporation). If the values were within $1 \mathrm{~mm}$, the mean of both diameters (maximum and minimum) was taken as the sample flow. If the maximum and minimum diameters of disks were not uniformly circular or were not within $1 \mathrm{~mm}$, the test was repeated. Five samples for each sealer $(n=5)$ were used, and the mean of 3 measurements for each sample, expressed to the nearest millimeter, was taken as the sample flow (group). According to ISO 6876/2001 specifications (9), for the flow test, a disk of at least $20-\mathrm{mm}$ diameter must be obtained.

\section{Statistical Analysis}

Data were statistically analyzed by analysis of variance (ANOVA) and Tukey test by using SPSS software 15.0 (SPSS Inc, Chicago, IL). The significance level adopted was $P<.05$.

\section{Radiopacity Test}

\section{Results}

Although the radiopacity value of Endosequence BC Sealer cement $(3.834 \pm 0.346 \mathrm{~mm} \mathrm{Al})$ has been significantly lower $(P<.05)$ than radiopacity of AH Plus $(6.936 \pm 0.462 \mathrm{~mm} \mathrm{Al})$, this value was above the recommendation by ISO $6786 / 2001$. The dentin presented radiopacity corresponding to $1.045 \pm 0.200 \mathrm{~mm} \mathrm{Al}$.

TABLE 2. pH Values Found at the Different Periods

\begin{tabular}{lccccc}
\hline & 3 Hours & 24 Hours & 72 Hours & 168 Hours & 240 Hours \\
\hline BC Sealer & $10.31^{\mathrm{a}}$ & $10.87^{\mathrm{a}}$ & $10.94^{\mathrm{a}}$ & $11.21^{\mathrm{a}}$ & $11.16^{\mathrm{a}}$ \\
AH Plus & $7.81^{\mathrm{b}}$ & $7.53^{\mathrm{b}}$ & $7.42^{\mathrm{b}}$ & $7.60^{\mathrm{b}}$ & 6.90 \\
Control & 6.90 & 6.90 & 6.90 & 6.90 \\
\hline
\end{tabular}

Values followed by different superscript letters indicate statistically significant differences according to ANOVA $(P<.05)$ in comparison between materials in same experimental time. 
TABLE 3. Calcium Ion Release (mg/L) Observed at the Different Periods

\begin{tabular}{lcccccc}
\hline & 3 Hours & 24 Hours & 72 Hours & 168 Hours & 240 Hours & Total \\
\hline BC Sealer & $.329^{\mathrm{a}}$ & $.204^{\mathrm{a}}$ & $.427^{\mathrm{a}}$ & $1.108^{\mathrm{a}}$ & $.517^{\mathrm{a}}$ & $2.585^{\mathrm{a}}$ \\
AH Plus & $.072^{\mathrm{b}}$ & $.182^{\mathrm{a}}$ & $.060^{\mathrm{b}}$ & $.635^{\mathrm{b}}$ & $.152^{\mathrm{b}}$ & $.797^{\mathrm{b}}$ \\
Control & .000 & .000 & .000 & .000 & .000 & .000 \\
\hline
\end{tabular}

Values followed by different superscript letters indicate statistically significant differences according to ANOVA $(P<.05)$ in comparison between materials in same experimental time.

\section{pH Analysis}

Endosequence BC Sealer cement presented alkaline $\mathrm{pH}$ in all experimental times, with maximum pH value in 168 hours (Table 2). AH Plus cement demonstrated slightly neutral $\mathrm{pH}$.

\section{$\mathrm{Ca}^{2+}$ Release}

Endosequence $\mathrm{BC}$ Sealer presented significantly greater release of $\mathrm{Ca}^{2+}(P<.05)$ than AH Plus cement. Table 3 describes the amount of $\mathrm{Ca}^{2+}$ released at the different experimental times. At 24 hours, there was no significant difference $(P>.05)$ between cements. After 168 hours, both sealers exhibited the highest release of $\mathrm{Ca}^{2+}$ (Table 3).

\section{Flow Analysis}

During the flow test no repetitions were required besides those standardized at the beginning of the experiment. According to the flow test, Endosequence BC Sealer cement demonstrated flow greater than $20 \mathrm{~mm}(26.96 \pm 0.68 \mathrm{~mm})$, which is in agreement with ISO $6786 / 2001$ recommendations. AH Plus presented a flow significantly lower than that of Endosequence BC Sealer $(21.17 \pm 0.39 \mathrm{~mm}$; $P<.05)$.

\section{Discussion}

Bioceramic materials have been introduced in the daily practice of dentistry mainly because of their high biocompatibility $(1,5,11)$ and strong antibacterial activity (6). The present study assessed the radiopacity and flow of new bioceramic cement, Endosequence BC Sealer, according to ISO 6876/2001 recommendations (9), and chemical properties such as $\mathrm{pH}$ and release of $\mathrm{Ca}^{2+}$ were also evaluated.

Radiopacity is an essential physical property that allows the viewing of the endodontic filling material through radiographic examination to check the obturation quality. The radiopacity value of Endosequence BC Sealer was $3.83 \mathrm{~mm} \mathrm{Al}$, which is in agreement with ISO $6786 / 2001$ recommendations (9) that established the minimum value of radiopacity of $3.00 \mathrm{~mm} \mathrm{Al}$. Although the constitution of both materials presents the same radiopacifier, zirconium oxide, the radiopacity of bioceramic sealer was significantly lower than that of AH Plus. The differences between radiopacities of root canal sealers tested in the present work might be analyzed by the presence of radiopacifying agents in each material. Duarte et al (10) evaluated the radiopacity of Portland cement with different radiopacifying agents. It was observed that this association is more radiopaque when the following radiopacifying agents were added in decreasing order: bismuth oxide, zirconium oxide, calcium tungstate, barium sulfate, and zinc oxide. Therefore, it could be inferred that depending on the amount and proportion of each radiopacifying agent, more or less radiopaque cement might be obtained (8). This possibly explains the fact that $\mathrm{AH}$ Plus cement presents another radiopacifier, calcium tungstate, which must increase the radiopacity value.

In regard to flow, both Endosequence $\mathrm{BC}$ Sealer and $\mathrm{AH}$ Plus demonstrated acceptable values according to ISO 6786/2001 recommendations (9), in which the minimal flow required for cements is $20 \mathrm{~mm}$. Flow is an important physical property that allows the cement to fill spaces of difficult access such as isthmus and accessory canals.
However, a high flow might increase the chance of the material extrusion toward the periapical region. Although it has been demonstrated that the Endosequence BC Sealer presents low cytotoxicity $(5,11)$, care should be taken to avoid overfilling. Furthermore, Hess et al (4) observed that files are unlikely to penetrate BC Sealer because of the hardness on setting of bioceramics, but in some cases unset sealer might be penetrable. They suggested that conventional retreatment techniques are not always able to fully remove BC Sealer. It was previously reported that "the key is using bioceramics as a sealer, not a filler" (3). Therefore, the inability to regain the working length and/or patency might compromise retreatment by preventing proper cleaning and shaping of the apical canal space, which might harbor bacteria.

According to the manufacturer, this cement shows high pH (12.8), high radiopacity, but the present study found that the maximum $\mathrm{pH}$ value was 11.21 after 10 days. An alkaline $\mathrm{pH}$ promotes the elimination of bacteria such as Enterococcus faecalis that might survive after chemomechanical preparation and induce or maintain periapical inflammation but do not survive in pH near $11(12,13)$. It has still been suggested that the mechanism of repair stimulation by deposition of mineralized tissue depends on $\mathrm{pH}$ and on the ability to release $\mathrm{Ca}^{2+}$ $(14,15)$. It was observed that moisture facilitates the hydration reactions of calcium silicates to produce calcium silicate hydrogel and calcium hydroxide, which partially react with the phosphate to form hydroxyapatite and water $(6,8,16,17)$.

The amount of $\mathrm{Ca}^{2+}$ released from Endosequence BC Sealer was far higher $(2.585 \mathrm{mg} / \mathrm{L})$ than that from AH Plus $(0.797 \mathrm{mg} / \mathrm{L})$, mainly after 7 days. A concordance was also observed between $\mathrm{pH}$ and the amount of $\mathrm{Ca}^{2+}$ released in both analyzed materials. A possible explanation for the high amount of $\mathrm{Ca}^{2+}$ released by bioceramic cements could be associated with setting reactions, including hydration reactions (A and B) of calcium silicates as described below (16):

(A) $2\left[3 \mathrm{CaO} \cdot \mathrm{SiO}_{2}\right]+6 \mathrm{H}_{2} \mathrm{O} \rightarrow 3 \mathrm{CaO} \cdot 2 \mathrm{SiO}_{2} \cdot 3 \mathrm{H}_{2} \mathrm{O}+3 \mathrm{Ca}(\mathrm{OH})_{2}$

(B) $2\left[2 \mathrm{CaO} \cdot \mathrm{SiO}_{2}\right]+4 \mathrm{H}_{2} \mathrm{O} \rightarrow 3 \mathrm{CaO} \cdot 2 \mathrm{SiO}_{2} \cdot 3 \mathrm{H}_{2} \mathrm{O}+\mathrm{Ca}(\mathrm{OH})_{2}$

The precipitation reaction (C) of calcium phosphate apatite is the following (17):

(C) $7 \mathrm{Ca}(\mathrm{OH})_{2}+3 \mathrm{Ca}\left(\mathrm{H}_{2} \mathrm{PO}_{4}\right)_{2} \rightarrow \mathrm{Ca}_{10}\left(\mathrm{PO}_{4}\right)_{6}(\mathrm{OH})_{2}+12 \mathrm{H}_{2} \mathrm{O}$.

In 168 hours, Endosequence BC Sealer presented the highest rate of $\mathrm{Ca}^{2+}$ release, and this fact might be related with the final setting time of this material that occurs between 160 and 240 hours in moist medium (5). Further studies must be performed to confirm this observation. Another interesting fact is that the release of calcium and hydroxyl ions from the calcium silicate-containing material might result in the formation of an apatite layer when it comes in contact with phosphate-containing fluids for 2 months. Thereby, formation of this interfacial layer develops a chemical bond between calcium silicatebased materials and dentinal walls (18). Therefore, it is anticipated that EndoSequence BC Sealer, which is based on a calcium silicate composition, has the potential to adhere chemically to dentin 
$(18,19)$, decreasing the marginal leakage and gaps as observed by Zhang et al (8).

Up to now, there are limited independent publications about the properties and applications of bioceramic root canal sealers in endodontics. Additional in vitro, ex vivo, and in vivo research must be conducted to evaluate the performance of this new material and to confirm its use in endodontic therapy.

In conclusion, the results of this study showed that the bioceramic endodontic cement, Endosequence BC Sealer, demonstrated suitable physicochemical properties.

\section{Acknowledgments}

The authors deny any conflicts of interest related to this study.

\section{References}

1. Damas BA, Wheater MA, Bringas JS, Hoen MM. Cytotoxicity comparison of mineral trioxide aggregates and EndoSequence bioceramic root repair materials. J Endod 2011;37:372-5.

2. Leal F, De-Deus G, Brandão C, Luna AS, Fidel SR, Souza EM. Comparison of the root-end seal provided by bioceramic repair cements and White MTA. Int Endod J 2011;44:662-8.

3. Koch K, Brave D. Bioceramic technology: the game changer in endodontics. Endodontic Practice 2009;2:17-21.

4. Hess D, Solomon E, Spears R, He J. Retreatability of a bioceramic root canal sealing material. J Endod 2011;37:1547-9.

5. Loushine BA, Bryan TE, Looney SW, et al. Setting properties and cytotoxicity evaluation of a premixed bioceramic root canal sealer. J Endod 2011;37:673-7.

6. Zhang H, Shen Y, Ruse ND, Haapasalo M. Antibacterial activity of endodontic sealers by modified direct contact test against Enterococcus faecalis. J Endod 2009;35:1051-5.
7. Pashley DH. Dynamics of the pulp dentin complex. Crit Rev Oral Biol Med 1996;7: 104-33.

8. Zhang W, Li Z, Peng B. Assessment of a new root canal sealer's apical sealing ability. Oral Surg Oral Med Oral Pathol Oral Radiol Endod 2009;107:e79-82.

9. International Organization for Standardization ISO 6876 dental root canal sealing materials. Geneva, Switzerland: International Organization for Standardization; 2001.

10. Duarte MAH, Kadre GDOL, Vivan RR, Tanomaru JMG, Tanomaru Filho M, Moraes IG. Radiopacity of Portland cement associated with different radiopacifying agents. J Endod 2009;35:737-40.

11. Zoufan K, Jiang J, Komabavashi T, Wang Y, Safavi KE, Zhu Q. Cytotoxicity evaluation of Gutta Flow and Endo Sequence BC sealers. Oral Surg Oral Med Oral Pathol Oral Radiol Endod 2011;112:657-61.

12. McHugh CP, Zhang P, Michalek S, Eleazer PD. pH required to kill Enterococcus faecalis in vitro. J Endod 2004;30:218-9.

13. Stuart $\mathrm{CH}$, Schwartz SA, Beeson TJ, Owatz CB. Enterococcus faecalis: its role in root canal treatment failure and current concepts in retreatment. J Endod 2006;32: 93-8.

14. Okabe T, Sakamoto M, Takeuchi H, Matsushima K. Effects of $\mathrm{pH}$ on mineralization ability of human dental pulp cells. J Endod 2006;32:198-201.

15. Holland R, Souza V, Nery MJ, Otoboni Filho JA, Bernabé PEF, Dezan Júnior E. Reaction of rat connective tissue to implanted dentin tube filled with mineral trioxide aggregate, Portland cement or calcium hydroxide. Braz Dent J 2001;12:3-8.

16. Richardson IG. The calcium silicate hydrates. Cem Conc Res 2008;38:137-58

17. Yang $Q$, Troczynski T, Liu D. Influence of apatite seeds on the synthesis of calcium phosphate cement. Biomaterials 2002;23:2751-60.

18. Sarkar NK, Caicedo R, Ritwik P, Moiseyeva R, Kawashima I. Physicochemical basis of the biologic properties of mineral trioxide aggregate. J Endod 2005;31: 97-100.

19. Shokouhinejad N, Gorjestani H, Nasseh AA, Hoseini A, Mohammadi M, Shamshiri AR. Push-out bond strength of gutta-percha with a new bioceramic sealer in the presence or absence of smear layer. Aust Endod J 2011;1-6. 